International Journal of Engineering \& Technology, $7(4.5)(2018) 700-702$
International Journal of Engineering \& Technology
SPC
Website: $\frac{w w w . s c i e n c e p u b c o . c o m / i n d e x . p h p / I J E T}{2}$
Research paper

\title{
Synthesis of silicon-based polymers for solid state lithium polymer batteries
}

\author{
Pratap Vangol ${ }^{1 *}$, Aronya Baksy ${ }^{2}$ \\ ${ }^{1}$ Delhi Public School Bangalore South \\ ${ }^{2}$ Delhi Public School Bangalore South \\ *Corresponding author E-mail: pratapppv@gmail.com
}

\begin{abstract}
This paper proposes the utilization of silicon based polymers for solid state lithium polymer batteries, thereby allowing batteries to be more rugged by decreasing electrolyte volatility and also making them eco-friendly.
\end{abstract}

Keywords: Silica Gel; Aerogel; Solid State Batteries; Lithium Polymer Batteries.

\section{Introduction}

In today's world, there is a demand for batteries which have a high energy to mass ratio and till date the only commercially viable options are Lithium based batteries. One of the major drawbacks of Lithium based batteries is that they are not very rugged and can spontaneously ignite when punctured. This is due to the volatile nature of the Lithium salt electrolytes. Our hypothesis: This volatility can be reduced when the electrolyte is adsorbed on the surface of a silicon based polymer. The polymer synthesized is a class of sub-critically dried aerogels (cross-linked polymers) having the monomer unit of $\mathrm{SiO} 2$. This polymer is formed by the polymerization reaction of sodium silicate with Hydrochloric Acid or Tartaric Acid. 0.1 Mol of Sodium Silicate was dissolved in 10$15 \mathrm{~mL}$ of water; $0.1 \mathrm{Mol}$ of tartaric acid was added to the previous solution ${ }^{[1][2] . ~ T h i s ~ i s ~ l e f t ~ a t ~} 27^{\circ} \mathrm{C}$ for a few minutes for the polymerization to complete.

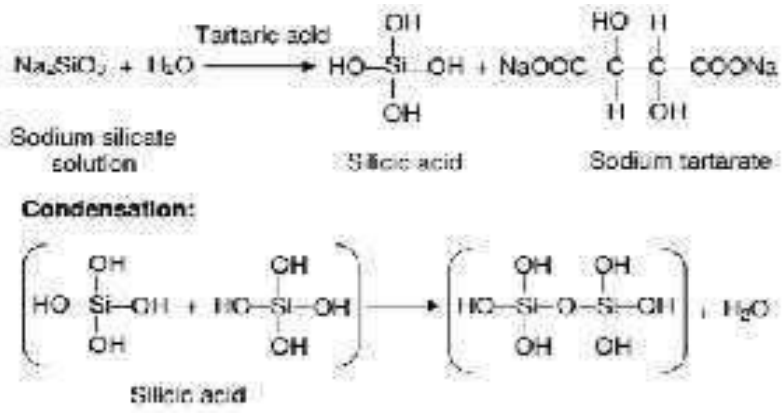

Fig. 1: Reaction of Sodium Silicate with Tartaric Acid.

\section{Gel and its properties}

1) The Solvent used during gelation.

2) The Temperature of gelation.

3) The Temperature of subcritical drying.

4) The $\mathrm{pH}$ of solution.
Changes in the above parameters results in changes in the polymerization pattern (i.e. determines the number of cross links in the polymer) which determines the pore sizes and degree of hydrophobicity of the resulting polymer. Since the battery's characteristics are dependent on the pore sizes and pore density, it is crucial to ensure that the nano-porous structure of the formed gel is intact (i.e the pores are unblocked and the pores have not collapsed). The above stated factor is entirely dependent on the solvent and temperature used for drying the gel. Three solvents were tried at a constant temperature and the area shrinkage was noted, as the shrinkage is a direct consequence of pore collapse. The observed results are shown in Table 1 .

Table 1: Variation of Length (L) and Breadth (B) in Mm

\begin{tabular}{|c|c|c|c|c|c|c|c|c|}
\hline \multirow[t]{3}{*}{ Time(min) } & \multicolumn{8}{|c|}{ Solvent } \\
\hline & \multicolumn{2}{|c|}{ None } & \multicolumn{2}{|c|}{ Acetone } & \multicolumn{2}{|c|}{ Toluene } & \multicolumn{2}{|c|}{$\begin{array}{l}\text { Hydrogen } \\
\text { peroxide }\end{array}$} \\
\hline & $\mathrm{L}$ & B & $\mathrm{L}$ & B & $\mathrm{L}$ & B & $\mathrm{L}$ & B \\
\hline 0 & 10 & 10 & 10 & 10 & 10 & 10 & 10 & 10 \\
\hline 5 & 9 & 8 & 8 & 8 & 9 & 10 & 10 & 10 \\
\hline 10 & 8 & 7 & 7 & 7 & 9 & 10 & 10 & 10 \\
\hline 15 & 7 & 6 & 7 & 7 & 9 & 10 & 10 & 10 \\
\hline 20 & 6 & 5 & 7 & 7 & 9 & 10 & 10 & 10 \\
\hline
\end{tabular}

The properties of the resultant gel can be adjusted by changing the following parameters:-

\section{Preparation of battery}

A Solid State Lithium Polymer battery (referred to as LiPo battery henceforth) is a type of battery which does not intrinsically have a liquid electrolyte; rather, its electrolyte is suspended within a polymer. According to the construction of the LiPo batteries, the electrolyte suspended in the gel is sandwiched between plates of graphite and Li foil as illustrated in Figure 2. The advantages of having a solid state LiPo battery is that they are more rugged as compared to regular LiPo batteries as the volatile electrolyte is suspended within the gel. 
This means that if the battery is punctured, it will not undergo a thermal runaway reaction which causes the battery to explode. Since the volatile electrolyte is suspended within a gel, it is less reactive and hence safer in general. Another major advantage of using the synthesized polymer for suspension of the electrolyte is the ability to control the maximum current generated by the battery. Current flows in a battery due to the mobility of ions in the solution. This mobility of ions can be easily varied by controlling the pore sizes of the gel. The maximum current generated by the cell I is directly proportional to $r$, where $r$ represents the radius of the formed pores.

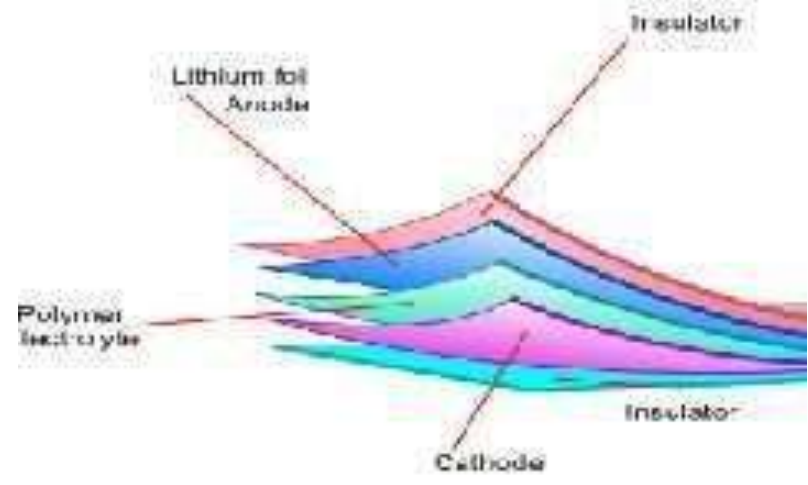

Fig. 2: Layered Structure of Lipo Battery.

\subsection{Results obtained and redesign}

The prototype batteries were made using glacial acetic acid as the electrolyte (due to lack of availability of Lithium metal and its salts) along with copper and aluminium electrodes as the anode and cathode respectively. The characteristics of the first battery are as shown in Table 2.

Table 2: Characteristics of Prototype Battery

\begin{tabular}{ll}
\hline Dimensions: & $250 \mathrm{~mm} \times 250 \mathrm{~mm} \times 2 \mathrm{~mm}$ \\
\hline Voltage: & $0.6 \mathrm{~V}$ \\
Current(max): & $2 \mathrm{~mA}$ \\
Resistance: & $300 \Omega$ \\
\hline
\end{tabular}

Due to the high internal resistance of the first prototype, the maximum current which can be delivered by the battery is of the order of micro amps. Therefore to reduce the internal resistance, two methods were tried:

1) Addition of exfoliated graphite during the synthesis of the gel.

2) Addition of charcoal powder during the synthesis of gel.

\subsection{Characteristics of cell with charcoal powder}

Figure 3 illustrates the discharge of the cell across a $177 \Omega$ resistor. From the above data, it is clear that the addition of charcoal powder results in a reduction of resistance by around 50\%. Data for this battery is as shown in Table 3 .

Table 3: Characteristics of Battery with Charcoal Powder

\begin{tabular}{ll}
\hline Dimensions: & $250 \mathrm{~mm} \times 250 \mathrm{~mm} \times 2 \mathrm{~mm}$ \\
\hline Voltage: & $0.6 \mathrm{~V}$ \\
Current(max): & $4.5 \mathrm{~mA}$ \\
Resistance & $133 \Omega$ \\
\hline
\end{tabular}

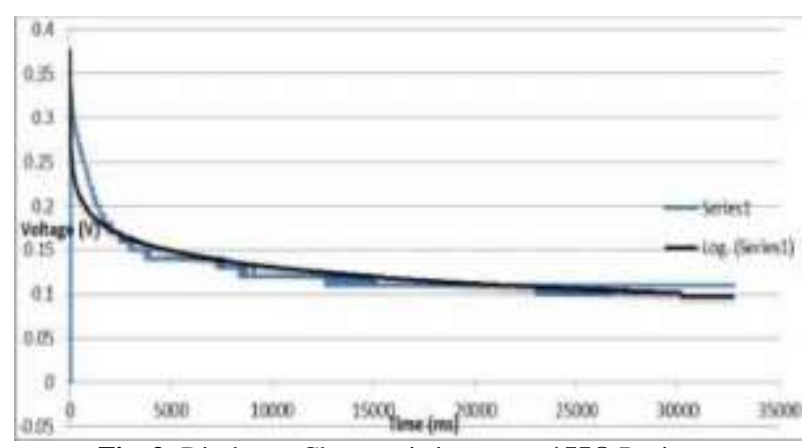

Fig. 3: Discharge Characteristics across $177 \Omega$ Resistor.

\subsection{Exfoliated graphite and characteristics of cell with exfoliated graphite}

Due to high internal resistance in initial prototypes, exfoliated graphite solution was added during the synthesis of the polymer. The exfoliated graphite was generated by two methods

1) Electrochemical exfoliation.

2) Chemical exfoliation using a method similar Hummersmethod for preparation of graphene.

The electro chemical exfoliation was carried out by immersing graphite electrodes in $0.07 \mathrm{M}$ solution of $\mathrm{Na} 2 \mathrm{SO} 4$ and passing $9 \mathrm{~V}$ and $1 \mathrm{~A}$ of current through them. The resulting exfoliated graphite was mixed with $30 \% \mathrm{H} 2 \mathrm{O} 2$ and was added to the reagents during formation of the polymer. The surface morphology of the exfoliated graphite was analysed through SEM. Figure 4, Figure 5 show the results obtained.

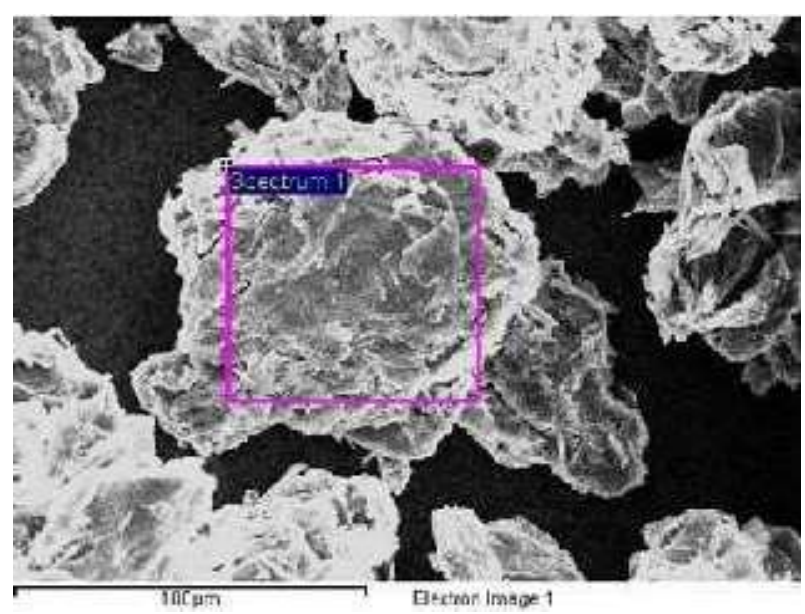

Fig. 5: EDAX Report of the Sample Shown in Figure 4.

To determine the effect of addition of exfoliated graphite on the efficiency of the battery, three different samples of gel were made with different amount of graphite solution in each: $1 \mathrm{~mL}, 2 \mathrm{~mL}$ and $3 \mathrm{~mL}$. The characteristics of each of the samples is as shown in Table 4,5and 6.

Table 4: $1 \mathrm{ml}$ of Exfoliated Graphite Solution

\begin{tabular}{ll}
\hline Dimensions: & $250 \mathrm{~mm} \times 250 \mathrm{~mm} \times 2 \mathrm{~mm}$ \\
\hline Voltage: & $0.6 \mathrm{~V}$ \\
Current(max): & $4.5 \mathrm{~mA}$ \\
Resistance: & $133 \Omega$ \\
\hline
\end{tabular}

\begin{tabular}{ll} 
& Table 5: $2 \mathrm{ml}$ of Exfoliated Graphite Solution \\
\hline Dimensions: & $250 \mathrm{~mm} \times 250 \mathrm{~mm} \times 2 \mathrm{~mm}$ \\
\hline Voltage: & $0.6 \mathrm{~V}$ \\
Current(max): & $7.6 \mathrm{~mA}$ \\
Resistance: & $78 \Omega$ \\
\hline
\end{tabular}

Table 6: $3 \mathrm{ml}$ of Exfoliated Graphite Solution

\begin{tabular}{ll}
\hline Dimensions: & $250 \mathrm{~mm} \times 250 \mathrm{~mm} \times 2 \mathrm{~mm}$ \\
\hline Voltage: & $0.6 \mathrm{~V}$ \\
Current(max): & $8.5 \mathrm{~mA}$ \\
Resistance: & $70 \Omega$ \\
\hline
\end{tabular}


Clearly the addition of exfoliated graphite increases the conduction of ions through the cell, thus reducing its resistance and increases its current delivery ability.

\section{Chemical inertness}

Since electrochemical cell reactions are redox reactions, the polymer must not react with strong oxidizing or reducing agents i.e. must not get reduced or oxidized. To test if the polymer would get reduced, a small sample of the polymer was placed in a watch glass

\section{Conclusion}

Therefore to conclude, the prototype cell prepared using the sy nthesized gel did not short circuit when punctured several times, as opposed to conventional cells, thus confirming our initial hypoth e-sis. The cells created generated $0.6 \mathrm{~V}$ which is $90 \%$ of the e xpected value according to the Nerst equation. This is due to contamin a-tion and inaccurate temperature control during the synthesis of the gel which results in many partially blocked or completely blocked pores. This can be circumvented through accurate temperature control during gel synthesis and controlling the amount of contamination.

An added advantage of this gel based batteries is that the silica gel used is biodegradable and also flexible in nature, paving the way for both biodegradable and flexible batteries.

and conc. $\mathrm{HCl}$ acid was added. Being a strong reducing agent, if it reacted with the polymer, it would liberate $\mathrm{Cl}$ gas. Experimentally, this did not occur and no reaction took place. To test the reactivity towards strong oxidizing agents, to a sample of the polymer in a watch glass, $\mathrm{KMnO} 4$ solution was added. On adding solution, decolorization was observed as $\mathrm{Mn}$ was reduced from $\mathrm{Mn}^{+7}$ to $\mathrm{Mn}$ ${ }^{+2}$ state. This was because the synthesized polymer was behaving as a catalyst and accelerated the degradation of $\mathrm{KMnO} 4$. Our hypothesis was tested by adding HNO3 to a fresh sample of the polymer. If the polymer was truly getting oxidized and not acting as a catalyst, it should have released NO2 gas. This was not the case and no gas was liberated. This observation thus confirmed our hypothesis that our polymer was truly inert towards oxidizing and reducing agents and hence could be used in making batteries.

\section{Acknowledgement}

We would like to thank Dr. M M Nayak and Ms.Prabha Hegde for guiding us during the entire period of our project. Special thanks to Aaina Arun for grammatical review.

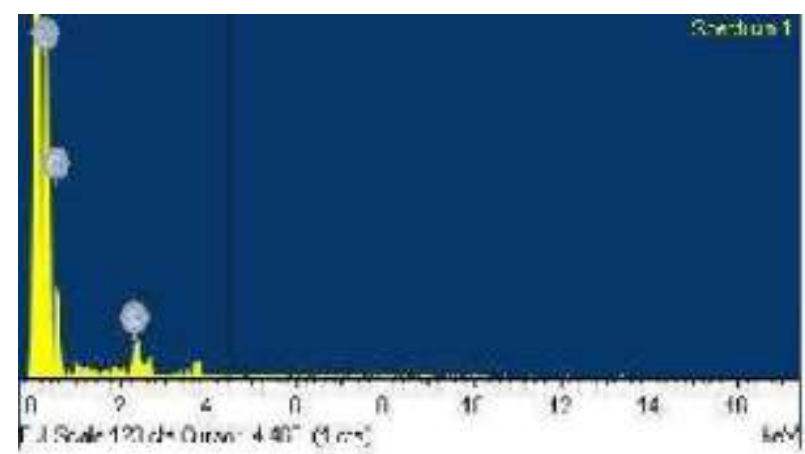

Fig. 4: SEM Image of Exfoliated Graphite.

\section{References}

[1] Uzma-Parveen Khwaja-Husain Bangi. Preparation and characterization of hydrophobic aerogels using inorganic precursor by ambient pressure drying. 2010.
[2] Alfred J Burzynski Robert E Martin. Preparation of silica gel, 1965. US3321276A. 